\title{
LA POLÍTICA BANCARIA EN LOS PAÍSES SUBDESARROLLADOS
}

DIa. BEATRIZ HERRERA GARCIA (*)

\section{INTRODUCCIÓN}

Los cambios acontecidos en el Japón que originaron la crisis bancaria -puesta de manifiesto como una fuerte contracción del crédito bancario que acompañó el brote final de la crisis financiera-, tenían sus origenes en la evolución de la banca y las finanzas en los Estados Unidos tres décadas antes. Hacia la década de los setenta comenzaba a producirse cambios profundos que habían comenzado allí. Dichos cambios generaban preocupación por la creciente fragilidad del sistema financiero (Mayer M., 1974).

Un aspecto importante de los cambios iniciados en Estados Unidos y Japón, décadas después, fue la disminución de los aspectos del crédito bancario referentes a las relaciones; es decir, fueron orientándose cada vez más a la realización de operaciones, en las cuales muchos bancos dejaron de ver la concesión y la vigilancia de préstamos como su función principal. Mientras, los bancos japoneses concedían y mantenían préstamos con el fin de obtener otros negocios con sus clientes.

Así, la estrategia de los bancos norteamericanos hacía hincapié en otorgar un préstamo y después vender el crédito a otros y, en la actualidad, dichos bancos no sólo se deshacen de hipotecas que seguidamente se reúnen para respaldar títulos con garantía hipotecaria; sino que también enajenan sus derechos en casi cualquier tipo de préstamo, tanto en los créditos de consumo como en los otorgados a las empresas.

En otras palabras, los bancos norteamericanos han procurado cada vez más vender una gama completa de servicios financieros a sus clientes, sean éstos empresariales o particulares. Al igual que las empresas de servicios financieros no bancarios, los bancos trataron de acrecentar sus ingresos por medio de actividades generadoras de comisiones y por la venta de servicios accesorios. Sin embargo, siguen proporcionando créditos a corto plazo y recibiendo depósitos a la vista en su enorme mayoría, aunque esas operaciones han dejado de ser una parte dinámica de la actividad bancaria debido a la difusión de los medios electrónicos de pago, entre otros.

Con ello se quiere afirmar que los bancos comerciales siguen teniendo una función que cumplir tanto en los países desarrollados como en los subdesarrollados, de los que cabe esperar que proporcionen una variada combinación de servicios

־) Vicerrectora Administrativa de la UNMSM. Doctorada en Ciencias Económicas y Políticas. 
financieros además de las operaciones tradicionales.

Este panorama que presenta la banca, en los países desarrollados, muestra un sector muy dinámico e innovador, aunque vulnerable a la crisis. Exige una firme supervisión para fomentar una competencia eficaz y una prestación no discriminatoria de los servicios bancarios. Esto es de igual aplicación-la supervisión y vigilancia-a los servicios bancarios en los países subdesarrollados, sobre todo a medida que la globalización trae hasta sus puertas la competencia de la banca transnacional.

\section{La Liberalización de las Tasas de Interés}

Desde el estallido de la crisis de la deuda en los países subdesarrollados (1982), surgió el tema referente a las tasas de interés, de la eliminación de los controles oficiales para dejarlos que sean determinados por el mercado. El aspecto que preocupaba era que las tasas de interés se mantenían artificialmente bajas en los países subdesarrollados y que, por ese camino, la economía estaba utilizando insuficientemente y distribuyendo mal el dinero y el crédito. Los países desarrollados también habían empleado controles sobre las tasas de interés; pero en gran medida los habían eliminado hacia finales de la década de los ochenta y se instaba a los países subdesarrollados a hacer lo mismo.

La argumentación sobre las tasas de interés se oscurecía un tanto por una mezcla de preocupaciones macroeconómicas y estructurales; pero, lo que se procuraba fundamentalmente, era la estabilización monetaria. Las tasas de inflación han caído efectivamente en el conjunto de los países subdesarrollados y han tenido un promedio alrededor del 11 por ciento anual desde 1997, en contraste con los porcentajes de tres cifras registradas antes.

Sin embargo, la liberalización de las tasa de interés no dio siempre los resultados que se esperaban. En algunos países las tasas de interés real no sólo pasaron a ser positivas, como se deseaba, sino que remontaron hasta niveles destructivamente elevados durante las luchas contra la inflación y, nuevamente con los acontecimientos que rodearon las crisis financieras y monetarias de varios países subdesarrollados, sobre todo asiáticos y latinoamericanos.

\begin{tabular}{|c|c|c|c|c|c|c|c|c|c|}
\hline \multicolumn{10}{|c|}{$\begin{array}{l}\text { Tasas de Inflación en los Países Subdesarrollados } \\
\text { (En porcentajes) }\end{array}$} \\
\hline & 1991 & 1992 & 1993 & 1994 & 1995 & 1996 & 1997 & 1998 & 1999 \\
\hline $\begin{array}{l}\text { Países Subdesarrollados } \\
\text { Por regiones: }\end{array}$ & 81,6 & 132,9 & 253,9 & 134,6 & 20,9 & 16,8 & 11,0 & 10,8 & 11,5 \\
\hline África & 96,0 & 172,3 & 111,9 & 244,7 & 40,4 & 36,6 & 13,3 & 9,3 & 9.2 \\
\hline Asia Oriental y Meridional & 7,7 & 7,0 & 8,3 & 12,0 & 9,9 & 6,7 & 4,5 & 7,9 & 4,7 \\
\hline Asia Occidental & 27,9 & 29,0 & 27,0 & 41,6 & 40,7 & 33,0 & 30,7 & 26,5 & 35,2 \\
\hline América Latina & 210,6 & 354,1 & 757,8 & 326,4 & 23,5 & 19,5 & 11,7 & 9,0 & 11,7 \\
\hline
\end{tabular}

Departamento de Asuntos Económicos y Sociales, N. U., N. Y., 1999. 
Estas preocupaciones por la liberalización de las tasas de interés se profundizaron más en el aspecto teórico. Se puso en tela de juicio la contribución que cabe esperar razonablemente de la liberalización de las tasas de interés para mejorar la eficiencia y el crecimiento de la economía, aspectos que tienen especial importancia en los países subdesarrollados.

El centro del argumento está en que los mercados bancarios no son eficientes, en sentido teórico, porque los mercados bancarios "no despejan", es decir, debido al problema de la información asimétrica, existe para los bancos un problema de selección adversa. La racionalidad en esas instituciones consiste en mantener los intereses por debajo del máximo que determinaría la igualdad entre la oferta y demanda. Por ejemplo, supongamos que un director de un banco puede aumentar las tasas de interés y que dos empresarios presentan proyectos con igual rendimiento, pero con diferente rasgo de insolvencia. El banquero financiaría los dos proyectos con tasas de interés baja y alta, pero el empresario del proyecto de bajo riesgo lo retiraría con la tasa de interés alta porque dejaría de ser viable. El empresario del segundo proyecto, en cambio, podría seguir adelante. Esto se debe a que los dos proyectos ofrecen supuestamente el mismo rendimiento, lo que significa que en caso de éxito sus réditos son mayores en el segundo proyecto (aunque es menor la probabilidad que el rédito se concrete). El segundo empresario comprende que si su proyecto fracasa no tendrá que reembolsar íntegramente el préstamo. En efecto, el banco comparte con el empresario el riesgo de que se deteriore su situación, pero no los beneficios si el proyecto tiene éxito. Por consiguiente, con las tasas de interés alta el banquero sólo tendría proyectos de alto riesgo para escoger entre ellos, lo que constituye el efecto de "selección adversa".
En lugar de ello, los bancos racionan el crédito entre los solicitantes de préstamos. Esto es importante porque la crítica que se hacía a los topes de las tasas de interés era que originaban un problema de racionamiento del crédito: el tope impedía que el precio del crédito aumentara hasta que la demanda de crédito equivaliera a la oferta. Ahora, se considera que el crédito quedará racionado aun sin los topes impuestos por medidas oficiales.

La conclusión más importante que se desprende de esta controversia es que no debe presumirse en modo alguno que los bancos comerciales efectúen una distribución del crédito que pueda calificarse como óptima en ningún sentido aplicable al desarrollo. Aun, así los gobiernos pueden encontrar útil privatizar sus bancos estatales y retirarse de la intervención directa en los mercados bancarios. Pero, no debe suponerse que una política totalmente pasiva respecto de la banca comercial privada -o una política limitada a los aspectos cautelares- será suficientemente favorable al desarrollo.

Por otro lado, tampoco se desprende que los gobiernos cumplirán necesariamente mejor que los bancos privados la labor de distribuir el crédito. En la mayoría de los casos la orientación gubernamental de la distribución del crédito distó mucho de ser eficaz, $y$ tampoco puede decirse que haya correspondido al interés público. En cambio, cuando funcionan bien puede considerarse que esos programas (se tratan de programas en los cuales los gobiernos intervenían en las decisiones de los bancos en materia de préstamos) forman parte de un conjunto de instrumentos utilizados por los gobiernos, ya que es imprescindible que la dirección del crédito se combine con otros factores para que los mecanismos tengan éxito. 
Esos factores complementarios no estaban en consonancia con la orientación fundamental de la política nacional e internacional y de desarrollo del sector financiero en los países subdesarrollados en el siglo XX, el cual consistía en impulsar un entorno financiero interno altamente liberalizado y profundizar la integración con el universo bancario y financiero internacional. Por lo que resulta poco probable que los ministerios de economía y los bancos centrales de los países subdesarrollados - para no referirse del sector bancario comercial, que ha tenido que aprender a funcionar en el nuevo entorno financiero internacional, en algunos casos con suma dificultad- toleren, en el corto plazo, una inversión de dicha estrategia de liberalización aplicada en la última década. Así, es posible que haga falta elaborar nuevos instrumentos de política para ese naciente entorno.

\section{La Política en Materia de Compe- tencia en el Sector Bancario}

Otro de los aspectos que tienen que abordar las autoridades gubernamentales en lo relacionado con el funcionamiento del sector bancario liberalizado consiste en asegurar el modo de competencia efectiva en el mercado interno de colocaciones. Los bancos grandes tienen probabilidades de contar con ventajas en este aspecto sobre los bancos nuevos o pequeños porque son conocidos por un circulo mayor de posibles acreedores y de ese modo pueden negociar mejores condiciones de préstamos. En países pequeños, que tienen un número limitado de grandes empresas y grupos bancarios, esto puede constituir un factor de importancia en la distribución del crédito.

Por otro lado el capital denominado de prestigio, de las empresas grandes y conocidas, puede ser importante pero adquiere especial significado cuando las normas de contabilidad y presentación de informes son pobres, $y$ la información que las empresas suministran no es digna de crédito. Se sostiene que las empresas que adquieren un capital de prestigio tendrán un incentivo financiero para mantenerlo mediante un comportamiento responsable, como el de eludir los riesgos excesivos (T. Hellmann y K. Murdock, 1997).

Desde el punto de vista de la política, la tarea más importante parece ser la de crear condiciones en las que los acreedores dependan menos de los indicios de solvencia basados en el prestigio y, de ese modo, están más abiertos a recibir a nuevos participantes.

Es decir, los servicios económicos del sector financiero pueden perfeccionarse hasta el grado de que la información necesaria para adoptar la decisión sobre un préstamo a un solicitante se normalice y despersonalice. Para los efectos, se cuentan con medios importantes como el establecimiento y la aplicación de códigos de transparencia mercantil, especialmente en lo referente a la adopción de normas convenidas de contabilidad y presentación de informes. Tales normas siempre pueden eludirse, por lo que también es preciso que exista una cultura de acatamiento de las normas.

Sin embargo, no deben exagerarse las perspectivas de mejor información y mayor transparencia. La experiencia de los inversionistas extranjeros directos es que en algunos países en los que actúa la información puede obtenerse y es digna de confianza, aunque resulte oneroso obtenerla. Pero, también hace falta un conocimiento del medio local para interpretarla. De este modo, aunque es preciso alentar la adopción 
de códigos convenidos internacionalmente en materia de transparencia, seguridad y oportunidad de la información, por sí solos no serán suficientes para descorrer la cortina cultural ni de homogenizar las prácticas mercantiles sobre las normas de ningún país determinado ni grupo de países, por ejemplo, la adopción de normas internacionales no eliminará todos los distintos tipos de normas culturales.

\section{La Política de Participación Extranjera}

La gama de actitudes respecto a la participación de los bancos extranjeros en la economía doméstica, así como la gama de prácticas realizadas en los países desarrollados a mediados de la década del 90 han llevado a los gobiernos a considerar de manera conveniente los niveles apropiados de participación de los bancos extranjeros en el mercado bancario de sus países. La evolución en Asia Oriental desde el comienzo de la crisis financiera en esa región y en América Latina, desde mediados de la década, parece indicar que la política evoluciona orientándose a una mayor función de las inversiones extranjeras en la banca. Pero, la forma en que cada gobierno recibe esa mayor presencia extranjera parece constituir un factor importante del éxito que se ha de tener (Ch. Weller, 2000).

Los bancos transnacionales atienden tradicionalmente a segmentos del mercado en que su presencia transnacional les da una clara ventaja competitiva. Una de las principales razones por la que los bancos transnacionales procuran entrar en un nuevo país, es con el propósito de prestar servicios a empresas también transnacionales que ya son sus clientes en otras partes del mundo. Además, los bancos transnacionales prestan servicios que los demás bancos no están familiarizados, o que no pueden prestar.
Entre esos servicios figuran los préstamos en moneda extranjera, las aceptaciones y garantías relacionadas con el comercio exterior, los préstamos otorgados por consorcios internacionales y los productos derivados. Debido a la índole de estos servicios, las grandes empresas nacionales se convierten en clientes de bancos transnacionales, mientras que las empresas menores tienden menos a requerir tales servicios. Finalmente, los bancos transnacionales ofrecen sus servicios a personas de gran fortuna con el fin de atraer nuevos depósitos y ofrecerles financiación de sus consumos. Esos servicios bancarios minoritarios que prestan los bancos transnacionales, comprenden servicios de corretaje, servicios relacionados con el ahorro, créditos hipotecarios, tarjetas de crédito y préstamos de consumo (Journal of Asian Economies, vol. 1, No. 1, 1990).

Por último, en la mayoría de los casos los bancos transnacionales no han ampliado sus actividades más allá de estos segmentos del mercado, aunque tal cosa parece estar cambiando. En particular, a medida que los mercados bancarios del país de origen se iban saturando y parecían existir todavía amplias oportunidades de lucro en países con economías emergentes, algunos bancos transnacionales comenzaron a ampliar su actividad en mercados internacionales para atender a medianas empresas y a familias de ingresos medianos. Así ha ocurrido recientemente en los mercados latinoamericanos, donde la entrada de bancos transnacionales en la actividad bancaria doméstica plantea un reto competitivo a los bancos locales.

Al respecto, en América Latina existe un historial de larga data de actividades bancarias extranjeras; pero, también hay un nuevo interés de los bancos extranjeros de instalarse en la región. Al parecer, habrán de participar en el mercado doméstico de 
manera diferente que sus predecesores y generarán, probablemente, efectos distintos.

En tanto, se prevé que la entrada de bancos transnacionales en el mercado en la forma tradicional como en la forma moderna habrá de favorecer las condiciones de competencia en el sector doméstico y la solidez de los bancos. Sin embargo, puede ocurrir que la entrada de bancos extranjeros -particularmente los de tipo tradicionaldebilite al sector bancario nacional y lo fuerce a aumentar los riesgos o bien reducir la calidad de su cartera de préstamos o frenar sus créditos, con la posibilidad de que las pequeñas y medianas empresas queden con menos acceso al crédito que antes. Los pasos que pueden llevar a estas consecuencias no deseadas comienzan con la política de liberalización, por la cual los propios bancos nacionales se ven en un entorno nuevo de mercado no reglamentado, en el que aparecen súbitamente otros bancos poderosos.

Los bancos nacionales necesitan nuevos capitales para poder competir con los bancos trasnacionales; pero, la presencia de éstos limita las posibilidades de aumentar el capital a través de la retención de utilidades para capitalizarlas. Ello se debe a que la mayor competencia reduce el margen entre las tasas activas y las pasivas, y con ello hace disminuir los beneficios que obtienen los bancos nacionales y las utilidades que pueden capitalizar por retención de las mismas. La importancia de estas últimas es que son la principal fuente de nuevos capitales, ya que suelen evitarse las aportaciones de capital oficial y las emisiones de nuevas acciones pueden ser dificiles.

Otro de los problemas para los bancos nacionales es que no sólo disminuirán las utilidades globales resultantes de los préstamos sino que, además, algunos de sus anteriores créditos de bajo riesgo pueden ser absorbidos por los nuevos bancos transnacionales instalados en el país. Los créditos a empresas trasnacionales o a grandes empresas nacionales con orientación internacional se cuentan generalmente entre los créditos de bajo riesgo, y son precisamente ésos los clientes para cuya atención los bancos transnacionales gozarán de una ventaja competitiva. Además, la liberalización tenderá, probablemente, a hacer aumentar las tasas generales de interés real en un inicio, lo que en todo caso desalentará a los prestatarios de bajo riesgo y bajo rendimiento, y desviará la demanda de préstamos hacia los solicitantes de mayor riesgo.

En ese contexto, los bancos nacionales, para mantener el nivel de sus préstamos, tendrán que tomar clientes de mayor riesgo. Si su respaldo de capital fuera adecuado para ello, ese aumento de riesgo general de su cartera de préstamos no representaría un problema; pero la premisa es que no están en condiciones de aumentar su capital. Además, la competencia de todos modos reduciría la rentabilidad de los bancos nacionales y, con ello, el valor de su capital. Para un banco que inicia el proceso con un capital insuficiente, la relación entre los préstamos y el capital puede descender a niveles peligrosamente bajos. Esos bancos tendrían poco que perder por el hecho de otorgar más préstamos de mayor riesgo y acrecentar los peligros generales del sistema bancario doméstico.

Los bancos que inician el proceso de liberalización con un respaldo de capital más sólido pueden responder a la pérdida de negocios de bajo riesgo con mayores garantías. Los elementos de juicio indican, en algunos países con economía emergente, que han efectuado la liberalización y se encuentran con la nueva competencia de bancos transnacionales. Los bancos nacionales en la realidad han tendido más a reducir sus préstamos. Esto significa que no sólo 
pierden grandes clientes a manos de bancos transnacionales sino que, además, optan por reducir el número de los clientes menores a los que atienden. El problema es que aunque pueden haber tenido un nivel prudente de capital para el volumen y la composición de sus préstamos efectuados en el entorno previo a la suspensión de reglamentaciones, ese capital sólo basta para respaldar un nivel menor de préstamos en el entorno más competitivo una vez que no se cuenta ya con los mejores créditos.

En resumen, concluimos diciendo que el problema de política se refiere a la forma de preparar a los bancos nacionales para el impacto de la eliminación de reglamentaciones y la entrada de bancos extranjeros, además de asegurar que se mantenga la disponibilidad de servicios bancarios a los clientes nacionales. En cuanto a esto último, los bancos nacionales muchas veces prestaban sus servicios a clientes de menor importancia económica y menos redituables como parte necesaria de un negocio que incluía ganancias importantes derivadas de grandes clientes. Es decir, antes de la eliminación de reglamentaciones, la atención de pequeños clientes (o de zonas rurales) podía estar implícitamente subvencionada mediante las ganancias obtenidas de los grandes clientes, que ahora se desplazan a los bancos transnacionales. En algunos casos pueden haberse otorgado subvenciones explícitas (o un banco estatal podía dedicar utilidades obtenidas de sus operaciones).

\section{BIBLIOGRAFÍA}

BRAINARD, Lawrence J.

1990. "Capital Markets in Korea and Taiwan: Emerging opportunities for foreign banks", Journal of Asian Economics, vol.1 Nro. l.

BENNETT, Adam.

1995. Behaviour of Nominal and Real Interest Rates. Fondo Monetario Internacional.

HERMAN, Barry y STALLINGS, Barbara. 1999. International Finance and the Developing Countries Liberalization, Crisis and The Reform Agenda, Global Financial Turmoil and Reform. Universidad de las Naciones Unidas.

HELLMANN, Th., y MURDOCK, K. 1997. Financial Sector Development Policy: The Importance of Reputational Capital and Governance. Oxford, Clarendon Press.

MAYER, Martin.

1974. The Bankers, Weybright and Talley. New York.

WELLER, Christopher. 2000. The Determinants and Effects of Multinational Banks in Developing and Transition Economies. DAES Universidad de las Naciones Unidas. 